\title{
Envelhecimento e representações sociais sobre a participação política em Portugal e no Brasil
}

\author{
Aging and social representations on political participation in Portugal and Brazil
}

\author{
Miriam Cabrera Corvelo Delboni ${ }^{1}$ \\ Silvia Virginia Coutinho Areosa ${ }^{2}$ \\ Paula Cristina Cadima Remoaldo ${ }^{3}$ \\ Maria Clara Costa Oliveira ${ }^{4}$
}

\begin{abstract}
RESUMO: Este estudo construído a partir de uma pesquisa qualitativa exploratória busca compreender as representações sociais sobre a participação política dos idosos em Portugal e no Brasil. Para delimitar o estudo foram escolhidas duas regiões, Braga em Portugal e Santa Maria no Brasil. Aplicou-se entrevistas semiestruturadas à 29 idosos (pessoas com mais de 60 anos) 14 em Braga e 15 em Santa Maria. As análises dos dados tiveram como embasamento a Teoria das Representações Sociais, conforme proposta por Serge Moscovici e a técnica de Análise de Conteúdo proposta por Laurence Bardin. Encontrou-se que há distinções nas formas de significar a participação em cada país e a interpretação e o sentimento dos idosos portugueses e brasileiros é de que não os querem presentes nos espaços de representação política.
\end{abstract}

Palavras-chave: envelhecimento; representação social; participação.

ABSTRACT: This study constructed from an exploratory qualitative research, search to understand the social representations about the political participation of the elderly in Portugal and Brazil. To delimited the study it were chosen two regions, Braga in Portugal and Santa Maria in Brazil. Semi-structured interviews were applied to 29 elderly (people with more than 60 years) 14 in Braga and 15 in Santa Maria. The analysis of the data had as basis the Theory of Social Representations, as proposed by Serge Moscovici and the Content Analysis technique proposed by Laurence Bardin. It was found that there are distinctions in the ways of meaning participation in each country and the interpretation and sentiment of the Portuguese and Brazilian elders is that they don't want them present in the spaces of political representation.

Keywords: aging; social representation; participation.

\section{Introdução}

O aumento demográfico da população idosa no mundo é uma realidade, considerando-se que, no ano de 2010, o número de pessoas com mais de 60 anos era de aproximadamente 600 milhões, sendo a projeção para 2050 de quase 2 bilhões de idosos (ONU, 2014). Com o aumento da esperança de vida, surgiram consequências inesperadas

\footnotetext{
${ }^{1}$ Doutora em Desenvolvimento Regional/UNISC. Docente Adjunta do Departamento de Terapia Ocupacional e do Programa de Mestrado em Gerontologia da Universidade Federal de Santa Maria - Santa Maria, RS, Brasil. E-mail: miriamdelboni@gmail.com.

2 Pós-Doutora em Serviço Social pela PUCRS. Docente do Departamento de Psicologia e do Programa de Mestrado e Doutorado em Desenvolvimento Regional da Universidade de Santa Cruz do Sul - Santa Cruz do Sul, RS, Brasil.

${ }_{3}^{3}$ Professora Doutora Associada com Agregação no Departamento de Geografia da Universidade do Minho - Braga, Portugal.

${ }^{4}$ Professora Doutora Associada com Agregação no Departamento de Educação da Universidade do Minho - Braga, Portugal.
} 
para os países, trazendo para a discussão novas questões e demandas por parte da população idosa relacionadas com saúde, moradia, previdência social, trabalho, dependência funcional, declínio cognitivo, necessidade de cuidados de longa duração, entre outras.

A projeção da transformação demográfica para as próximas décadas torna-se um desafio para os governantes e para a sociedade civil na atualidade e num futuro próximo. Esses temas foram discutidos e assumidos como diretrizes para as políticas públicas dos países signatários da ONU, na conquista de um envelhecimento saudável para o futuro dessa população e de suas garantias sociais. Entende-se que, apesar de todos os esforços da Organização das Nações Unidas (ONU) para construir diretrizes políticas para essa população, a desigualdade social e as diversidades geográficas, entre outras, constituem barreiras para a consolidação dessas ações.

Segundo Veras (2009), a adoção de medidas de proteção à saúde está longe de ser realizada de forma equitativa diante das particularidades dos contextos socioeconômicos, políticos e culturais, apresentados pelos diferentes países e pelas diferentes regiões. Essas particularidades acabam resultando no que se define por desigualdades na área da saúde não só para o atendimento ao idoso, mas para todos os segmentos da sociedade. Ao examinarem-se essas questões, compreende-se que não somente as variações socioeconômicas as definem, mas também outros fatores, como o local de residência, a etnia, o estado marital e até mesmo o gênero, que podem ser considerados como elementos condicionadores dessas desigualdades na saúde, considerando-as como multifatoriais (Remoaldo \& Nogueira, 2012).

Nesse contexto, na atualidade, a compreensão do envelhecimento é muito mais profunda e articulada com inúmeros outros processos. Do ponto de vista do desenvolvimento de uma sociedade, crianças/jovens e adultos/idosos fazem parte de uma mesma história, sendo primordial essa compreensão para alcançar o futuro que se almeja, que é a qualidade de vida de seus cidadãos. Para isso, também é necessário destacar que cada sociedade é construída por sua história e por suas contradições e que todos fazem parte dessa complexidade, cada qual com suas particularidades e subjetividades, refletidas na forma de organização de suas práticas sociais cotidianas. Essas práticas, por sua vez, são reguladas por leis, normas e condutas que se manifestam e se materializam de formas diversas na sociedade (Alcântara, Camarano \& Giacomim, 2016).

O ser humano constrói representações sociais porque precisa saber o que o faz relacionar-se com o mundo à sua volta, necessitando ajustar-se e localizar-se, identificando problemas e propondo soluções. Isto se associa ao fato de que diante de eventos, coisas, pessoas ou ideias, as suas respostas não serão apenas automatismos. O ser humano não está isolado em vazios sociais, mas sim em um mundo compartilhado com outros, nos quais se sustentará (ora convergindo, ora divergindo) para compreender, gerenciar e afrontar o mundo à sua volta (Jodelet, 2001).

De outra forma, compreende-se que os movimentos individuais e sociais ocorrem em diferentes contextos, refletindo na maneira de se constituir do cidadão idoso, ator social e político desse processo. Essas trajetórias históricas produziram maneiras de ser e estar, bem como de participação em espaços políticos e como representantes de um segmento da sociedade singulares no Brasil e em Portugal. 
Johnson, Escosteguy e Shulmann (1999) explicam que a subjetividade não é dada, mas produzida, e que é no cotidiano que ela se materializa a partir da leitura que cada pessoa faz do mundo, e na forma de atuar no contexto social em que vive, inserida nas subjetividades das relações sociais. Portanto, cada ator social que compõe o processo de implantação das políticas públicas de saúde está imbuído de subjetividades, que, por sua vez, se constituem de forma singular para cada um.

Considerou-se que essas subjetividades estão ligadas aos processos históricos, políticos, econômicos e culturais de cada região e país e refletidas no cotidiano e nos discursos de cada ator social. Assim, não se pode considerar apenas as formas de poder e as regulações nas sociedades, mas devem ser consideradas as percepções desses atores enquanto participantes da construção política de saúde nos países pesquisados. Ao considerar a subjetividade, lança-se o olhar sobre as percepções, os significados, o conteúdo do "senso comum", as representações, aquilo que é objeto de estudo da Teoria das Representações sociais que segundo Jodelet (2007) são saberes ou conhecimentos, socialmente elaborados e partilhados, com objetivos práticos e que contribuem para a construção de realidades comuns a um grupo social.

..., a compreensão da dinâmica das representações sociais, bem como dos mecanismos que a constituem, obriga a que se analise sua historicidade sob risco de considerá-las um fenômeno anistórico constituído em um contexto genérico o que, de modo geral, tem contribuído para a existência de pesquisas, tanto no âmbito educacional como em outras áreas, cada vez mais descritivas e pouco interpretativas (Bôas, 2010, p.382).

A questão social do idoso é bastante complexa, refletindo-se no seu modo de viver. Embora a pessoa idosa em geral não esteja vocacionada para a vida política, encontra-se inserida no âmbito político de sua ação cotidiana na conquista de suas demandas. Desse modo, partiu-se do princípio de que esse fenômeno não é homogêneo e há demarcações subjetivas inseridas tanto nos contextos pessoais de cada idoso como nos contextos externos (políticos, econômicos, ambientais, sociais e históricos), de maneira a constituir a sua participação como protagonista desse processo.

Considerou-se a participação do idoso em espaços que permeiam o exercício de cidadania - tais como sindicatos, organizações e associações de idosos -, bem como nos que garantem o controle das políticas de saúde, que seriam os Conselhos do Idoso. Sendo assim, a participação é vista como uma prática social e remeteu-se à dimensão da relação do idoso com outros atores sociais para a tomada de decisões coletivas, que deve ser entendida como um processo em constante construção, e como um exercício pleno da cidadania. Entende-se, logo, que ela não está centrada apenas no contexto pessoal do idoso, visto que se constrói e se consolida na interação das redes de relações presentes no tecido social e se cristaliza nas formas organizativas da sociedade (Paz, 2001).

Portanto, a problemática que este artigo abarca é de que forma se organizam os espaços políticos e como ocorre a participação política dos idosos nesses espaços em duas cidades: Braga em Portugal e Santa Maria no Brasil, construindo representações sobre o que é participar e como o idoso se sente ao participar destes espaços.

\section{Método}

Este artigo apoia-se na Teoria das Representações Sociais (RS) que são consequências das interações humanas que advém dos encontros das pessoas nos diferentes espaços 
cotidianos. Desse modo, o pensamento coletivo se individualiza a partir do momento que as RS influenciam o comportamento do indivíduo participante de uma coletividade, orientando as práticas humanas (Moscovici, 2007). Nesse sentido, é importante conhecer as RS da participação dos idosos em espaços políticos de ambos os países, sobretudo se elas são positivas e capazes de potencializar a participação social em saúde.

Segundo Moscovici (2007), as RS são geradas por dois processos cognitivos, ancoragem e objetivação, traduzidos como formas de atender a memória. A ancoragem diz respeito a introduzir as novas ideias ou estranhas em categorias já existentes na memória (classificação), ou seja, colocá-las em um contexto familiar e dar nome a elas (nomeação). No segundo, a objetivação, significa a materialização de uma abstração, é a reprodução de conceitos e imagens no mundo exterior (Moscovici, 2007). Desta feita, parte-se do pressuposto de que, ao conhecer o conteúdo das RS dos idosos sobre participação, é possível compreender as condutas e práticas que orientam à participação política em cada país.

\section{Participantes}

\section{Braga - Portugal}

No caso do município de Braga, foram concretizadas catorze entrevistas a idosos participantes como usuários ou integrantes das associações e que frequentavam serviços de saúde e Centros Comunitários ou de Convivência (Figura 1). Os idosos desse grupo são identificados pelas siglas IP (Idoso Português), seguido pelo número de referência, na ordem em que foram entrevistados.

\begin{tabular}{|c|c|c|c|c|c|}
\hline Identificação & Local de participação ou entrevista & Idade & Gênero & $\begin{array}{c}\text { Grau de } \\
\text { instrução }\end{array}$ & $\begin{array}{l}\text { Profissão anterior/ } \\
\text { aposentadoria }\end{array}$ \\
\hline IP1 & Hospital de Braga & 65 & $\mathrm{~F}$ & Primário & Dolar \\
\hline IP2 & Associação dos Reformados de Braga & 69 & $\mathrm{M}$ & Primário & Motorista \\
\hline IP3 & Unidade de Saúde Gualtar & 83 & $\mathrm{M}$ & Primário & Lavrador \\
\hline IP4 & Unidade de Saúde Gualtar & 77 & $\mathrm{~F}$ & Secundário & Costureira \\
\hline IP5 & Centro Social e Comunitário São Adrião & 78 & $\mathrm{~F}$ & Secundário & Dolar \\
\hline Identificação & Local de participação ou entrevista & Idade & Gênero & $\begin{array}{l}\text { Grau de } \\
\text { instrução }\end{array}$ & $\begin{array}{c}\text { Profissão anterior/ } \\
\text { aposentadoria }\end{array}$ \\
\hline IP6 & $\begin{array}{l}\text { Centro Paroquial e Social de São José do } \\
\text { São Lázaro }\end{array}$ & 77 & $\mathrm{M}$ & Secundário & Comerciante \\
\hline IP7 & $\begin{array}{c}\text { Centro Paroquial e Social de São José do } \\
\text { São Lázaro }\end{array}$ & 71 & $\mathrm{~F}$ & Secundário & Bancária \\
\hline IP8 & Irmandade Santa Cruz - Largo do Souto & 76 & $\mathrm{M}$ & Secundário & Motorista de táxi na França \\
\hline IP9 & Irmandade Santa Cruz - Largo do Souto & 77 & $\mathrm{~F}$ & Secundário & Comerciante \\
\hline IP10 & Irmandade Santa Cruz - Largo do Souto & 79 & $\mathrm{M}$ & Secundário & Comerciante \\
\hline IP11 & $\begin{array}{l}\text { Associação Social Cultural Recreativa e } \\
\text { Desportiva de Nogueiró. }\end{array}$ & 69 & $\mathrm{~F}$ & Secundário & Do lar \\
\hline IP12 & $\begin{array}{l}\text { Associação Social Cultural Recreativa e } \\
\text { Desportiva de Nogueiró. }\end{array}$ & 71 & $\mathrm{~F}$ & Primário & Dolar \\
\hline IP13 & $\begin{array}{l}\text { Associação dos Reformados Pensionistas } \\
\text { Idosos de Vale Cávado }\end{array}$ & 72 & $M$ & Superior & Farmacêutico \\
\hline IP14 & $\begin{array}{l}\text { Associação dos Reformados da } \\
\text { Previdência do Minho }\end{array}$ & 73 & M & Secundário & Construtor civil \\
\hline
\end{tabular}

Figura 1 - Perfil dos idosos portugueses entrevistados em Braga. Fonte: Elaborado pelas autoras a partir das informações colhidas dos entrevistados. 
Dos 14 idosos entrevistados em Braga, em relação ao gênero, foram sete homens e sete mulheres, cuja idade variou entre 65 e 83 anos. Quanto ao grau de instrução, quatro tinham o ensino primário, nove o ensino secundário, um o ensino superior e todos estavam aposentados.

\section{Santa Maria - Brasil}

Em Santa Maria, foram concretizadas quinze entrevistas aos idosos usuários de diversos espaços associativos do município e a uma idosa participante do Conselho Municipal do Idoso (COMID). Para identificar esse grupo de idosos foram utilizadas as siglas IB (Idoso Brasileiro), seguidas pelo número da ordem da entrevista (Figura 2).

\begin{tabular}{|c|c|c|c|c|c|}
\hline Identificação & $\begin{array}{c}\text { Local da participação ou } \\
\text { entrevista }\end{array}$ & Idade & Gênero & Grau de instrução & $\begin{array}{c}\text { Profissão anterior/ } \\
\text { aposentoria }\end{array}$ \\
\hline IB1 & $\begin{array}{l}\text { Grupo Associação } \\
\text { Cabelos de Prata }\end{array}$ & 75 & $\mathrm{M}$ & Secundário & Militar \\
\hline IB2 & $\begin{array}{l}\text { Grupo Associação } \\
\text { Cabelos de Prata }\end{array}$ & 68 & $F$ & Primário & Cuidadora de Idosos \\
\hline IB3 & $\begin{array}{c}\text { Grupo De Bem com a } \\
\text { Vida }\end{array}$ & 76 & $\mathrm{~F}$ & Secundário & Costureira \\
\hline IB4 & $\begin{array}{c}\text { Unidade de Saúde } \\
\text { Gualtar }\end{array}$ & 80 & $\mathrm{M}$ & Primário & Construção Civil \\
\hline IB5 & $\begin{array}{c}\text { Grupo Grisalhas da } \\
\text { Primavera }\end{array}$ & 67 & $\mathrm{~F}$ & Secundário & Do lar \\
\hline IB6 & $\begin{array}{c}\text { Grupo Grisalhas da } \\
\text { Primavera }\end{array}$ & 61 & $F$ & Secundário & Do lar \\
\hline IB7 & Grupo Reviver & 67 & $\mathrm{~F}$ & Primário & Cuidadora \\
\hline IB8 & Grupo Reviver & 73 & $\mathrm{M}$ & Secundário & Representante Comercial \\
\hline IB9 & $\begin{array}{c}\text { Grupo Novo Estilo de } \\
\text { Vida }\end{array}$ & 80 & $\mathrm{M}$ & Superior & $\begin{array}{l}\text { Dentista } \\
\text { Militar }\end{array}$ \\
\hline IB10 & $\begin{array}{c}\text { Grupo Novo Estilo de } \\
\text { Vida }\end{array}$ & 61 & $\mathrm{~F}$ & Secundário & Do lar \\
\hline IB11 & Grupo Anos Dourados. & 78 & $\mathrm{~F}$ & Primário & Agricultora \\
\hline IB12 & Grupo Anos Dourados. & 86 & $\mathrm{M}$ & Primário & Agricultor \\
\hline IB13 & $\begin{array}{c}\text { Grupo Mente Sã, Corpo } \\
\text { São }\end{array}$ & 70 & $\mathrm{~F}$ & Superior & Artesã \\
\hline IB14 & $\begin{array}{c}\text { Grupo Mente Sã, Corpo } \\
\text { São. }\end{array}$ & 72 & $\mathrm{M}$ & Secundário & Comerciante \\
\hline IB15 & COMID & 71 & $\mathrm{~F}$ & Superior & Professora \\
\hline
\end{tabular}

Figura 2 - Perfil dos idosos brasileiros entrevistados em Santa Maria. Fonte: Elaboradora pelas autoras a partir das informações colhidas dos entrevistados.

Foram entrevistados 15 idosos, nove mulheres e seis homens, com idades que variaram entre 61 a 86 anos. Quanto ao grau de instrução quatro tinham grau superior e os demais o secundário. Todos aposentados.

\section{Instrumento}

Utilizou-se uma entrevista semiestruturada para os idosos com 8 pautas que envolviam 0 assunto sobre participação política. As entrevistas foram integralmente gravadas em registro de áudio (com o consentimento dos entrevistados) e posteriormente transcritas. Em seguida, foram sujeitas a uma análise temática e categorial de conteúdo (Bardin, 2007), com vista a descrever e a interpretar os significados dos discursos recolhidos. Após a análise dos dados foi construída uma grade com os temas e categorias 
representativas das entrevistas. Desta forma, as RS e as manifestações sobre a participação dos idosos estão diretamente ligadas ao contexto social, à época e ao grupo de sujeitos que as compartilham. E no entendimento de Jodelet (2001) elas atuam ativamente na orientação de suas práticas e na interpretação que eles fazem do mundo.

\section{Coleta e Análise de dados}

A análise de conteúdo dos dados (Bardin, 2007) foi operacionalizada em três etapas: a primeira delas, a pré-análise, consistiu na escolha dos materiais a serem analisados na sua relação com os objetivos inicialmente propostos, buscando elaborar os eixos de análise. Nessa fase, o material coletado foi alvo de leitura e reflexão exaustiva, em confronto com os objetivos e com a base teórica adotada. O material foi organizado de forma a responder a algumas normas de validade (exaustividade, representatividade, homogeneidade e pertinência), tendo sido definidas as formas de organização e as categorias de análise (Minayo, 2010).

Na segunda fase, a da exploração, o material foi codificado, mensurado, organizado e classificado, de acordo com os princípios formulados na primeira fase. Na terceira e última fase, a do tratamento dos resultados obtidos e sua interpretação, o material foi analisado com base na Teoria das Representações Sociais buscando compreender o fenômeno da participação política de cada grupo de idosos (PT/BR), a partir da construção de sua realidade simbólica (Moscovici, 2003).

\section{Discussões}

Costuma-se definir representações sociais como sistemas de interpretação que direcionam a relação com os outros, regendo e ordenando condutas e comunicações sociais. Elas intervêm em processos variados, como difusão e assimilação de conhecimentos, na construção individual e coletiva, na elaboração das identidades pessoais e sociais e na expressão de grupos e transformações sociais (Jodelet, 2001).

Por estes motivos, também é intitulado como um saber do senso comum, ingênuo ou natural, diferenciando-se do saber científico. No entanto, é tido como objeto de estudo tão legítimo quanto este outro, tendo em vista sua relevância na vida social e esclarecimento que presta sobre processos cognitivos e interações sociais (Jodelet, 2001).

Para os entrevistados, a participação é um tema relevante e de importância. Há uma maioria de idosos que participam em atividades diversas - sociais, comunitárias, avaliativas e política. Há, sem dúvida alguma, um reconhecimento da importância dessa participação dos idosos nas questões políticas. No entanto, sobretudo nos idosos portugueses, encontrou-se uma resistência para se falar sobre o assunto, dificuldade em se posicionarem, além de terem apontado que, apesar de saberem da relevância, acreditam que é uma atividade destinada somente a algumas pessoas.

$\mathrm{Na}$ dimensão sociológica da participação cidadã nos assuntos públicos tem como proposta reduzir a distância entre representantes e representados e visa propiciar uma ação política mais igualitária, baseada em grande número de grupos sociais que, articulados em 
rede, contribuem para orientar as ações governamentais no sentido de atender às necessidades da maioria dos cidadãos (Aguiar, 2016; Vedovate \& Dellore, 2016).

Mesmo previsto na legislação, os idosos sofrem barreiras e empecilhos para participarem e referem-se aos espaços do Conselho Municipal de Saúde de Santa Maria como um local onde não entendem do que estão falando ou não se sentem empoderados para falar o que pensam. Tampouco identificam resolutividade nos assuntos abordados no Conselho Municipal:

Eu muitas vezes fui, mas tu tem que ter bastante palavras e quando a gente não tem muito, não é formada em Direito, tu tem que te encolher, fica difícil. (Idosa, 86 anos, IB12).

Olha, vou te dizer bem sincera, não me motiva muito, sabe, as conversas são sempre enroladas $e$ a mesma coisa, então pra mim eu acho que nunca tem uma solução, faz projeto, faz isso, faz aquilo, mas a coisa nunca anda. (Idosa, 70 anos, IB13).

Para Bernardes (2007), não basta ter a compreensão de que os Conselhos Municipais são locais que favorecem a conquista da cidadania, ou seja, a cidadania participativa e representativa, mas que são o esforço do coletivo em dar voz ao idoso. Quando se potencializam esses espaços, dãose novas formas de cidadania à velhice, abrindo caminhos e caminhando junto ao idoso para viabilizar a sua inserção nesse espaço social vital. No entanto, nem sempre eles se acham pertinentes a esses espaços instituídos para eles, como observa-se nas falas de duas idosas brasileiras:

É muito confuso, muito confuso, é uma bagunça total, pra mim, né? (Idoso, 75 anos, IB1).

Olha eu não só, nem gosto muito de falar em politica, por que a gente é bastante antigo, morava para o interior, não via nada disso, agora que a gente tá velho que a gente vê tantas coisas que não devia de ser assim, né? Então a gente ouve, mas não pode discutir também, não pode fazer nada, não sabe, não vai discutir, né? (Idosa, 76 anos, IB3).

Jodelet (2001) expõe que o sujeito do conhecimento, seja enquanto indivíduo ou de um grupo e sua experiência, se traduz nas condições sociais de sua produção e de sua circulação a uma prática já que este conhecimento se oferece como versão do mundo que gere a vida cotidiana e social. Portanto, nas relações sociais e principalmente nas relações de poder, a noção da representação social constitui uma possibilidade de mudança, visto que, identificam-se situações como as descritas pelos idosos acima como potencialmente frágeis e inseguras para participar de um espaço que lhes é de direito. Ou como pode-se observar que a idosa abaixo identifica a importância da participação dos idosos e o quanto esses devem ocupar os espaços de direito:

Tem muitos que tem muita experiência e é uma coisa que não é levada a sério. Eles têm que tomar mais a frente pra eles poderem levar mais adiante algumas coisas por que aqui o Brasil o que que tá, tu vê, tu vê, botam esse políticos lá, esses políticos lá o que que eles fazem, é encher os bolsos deles, e se esquece de tudo. (Idosa, 62 anos, IB2).

Por outro lado, os fatores pessoais são destaque para esse idoso português, que se posiciona como uma pessoa que sempre gostou de estar e participar:

Eu acho que é uma questão pessoal, eu sempre gostei, sempre me dediquei a liderar, eu gosto, sempre fui assim, não sei ficar parado, pronto, é isso. Quem quer vem, quem não quer não vem, pronto (Idoso, 69 anos, IP2).

Já para essa senhora portuguesa, os fatores pessoais se dividem em dores no corpo e em sua preferência por estar quieta, sem envolvimento com nenhuma ação: 
Às vezes o mau tempo, as dores vêm mais fortes, me boto a ficar quietinha em casa, mas não gosto. (Idosa, 77 anos, IP3).

No caso dessa outra senhora, também portuguesa, a dificuldade para participar está além de suas dores pessoais, pois há as atitudes de desvalorização daqueles que "os queiram lá":

Ihh, as dificuldades são muitas, minha senhora, há muita coisa que um idoso precisa passar, (risos), as dores são as principais delas... outra cousa é que os queiram lá [...] (Idosa, 71 anos, IP7).

Portanto, tanto idosos brasileiros como portugueses não se sentem pertencentes aos espaços institucionalizados para a participação deles, quer sejam nos Conselhos no Brasil ou na participação avaliativa dos equipamentos de saúde em Portugal. Conforme analisado nas entrevistas, os idosos identificaram barreiras atitudinais dos que estão na gestão dos processos ou desestímulo por verem pouca efetividade resolutiva das ações propostas nesses espaços. Por outro lado, há aqueles para quem a motivação para participar está inserida no contexto pessoal de cada um, ou seja, o desejo de participar estaria vinculado às questões internas de cada sujeito e que o constituem desde outras fases da sua vida. Assim, a participação seria um processo natural, contido no desejo interno de querer ou não estar presente nas ações discutidas nesses espaços. Isto demonstra o quanto as representações sociais são importantes no cotidiano: "elas nos guiam na maneira de nomear e definir em conjunto os diferentes aspectos de nossa realidade cotidiana, na maneira de interpretá-los, estatuí-los e, se for o caso, de tomar uma posição a respeito e defendê-la" (Jodelet, 2001, p. 17).

Faleiros (2016) explica que a desvalorização do idoso é frequente. As sociedades capitalistas valorizam o trabalho e o consumo, e, nesse sentido, o idoso e a sociedade tendem a vê-lo como inútil ou sem valor. Dessa forma, a desvalorização insere-se tanto na sociedade como em sua própria percepção, como indivíduo menos válido e excluído.

Os movimentos sociais por lutas de classe são praticamente inexistentes em Portugal, talvez herança de um governo de ditadura do passado, contrariamente ao que ocorre no Brasil, onde os movimentos de luta por reconhecimento são constantes. Os movimentos sociais dos idosos no Brasil, segundo Paz (2001), tiveram início nas décadas de 1930/1950, enquanto eram trabalhadores, sendo essas lutas restritas às questões específicas de suas categorias profissionais. Os trabalhadores eram organizados em torno das Caixas de Pecúlio (CAPs) ou Institutos de Previdência Social (IAPs), de acordo com suas profissões. Essa forma de organização respeitava as características de cada profissão e subsidiava também as pensões, os pecúlios, os serviços de assistência e as aposentadorias.

Por volta dos anos 1960 houve a unificação desses institutos, que passaram a ser designados de "sistema previdenciário": o Sistema Nacional de Previdência e Assistência Social (Sinpas), que unificou o Instituto Nacional de Previdência Social (INPS) e o Instituto Nacional de Assistência Médica e Previdência Social (Inamps). Em decorrência dessa união, muitas dificuldades surgiram, inclusive atraso e perdas de proventos, e, devido ao período de ditadura estabelecido no País, calaram-se as vozes dos trabalhadores e, por consequência, dos aposentados. Em 1991, já num país democrático e logo após a Constituição de 1988, que garantia os benefícios de aposentados e pensionistas ao mesmo nível do poder aquisitivo, com o salário mínimo como referência, foi promulgada a Lei no 
8.222, que retirava o direito dos aposentados ao referido ajuste dos trabalhadores, de $147,06 \%$.

A mobilização dos aposentados, pensionistas e demais beneficiários da Previdência Social por meio de suas organizações, a ampla repercussão da mídia e a atuação decisiva do Judiciário tornaram possível a vitória do chamado "Movimento dos 147\%". "A luta pelos 147\%", como ficou popularmente conhecida, tornou visível as questões da velhice e do envelhecimento humano no país, bem como a mobilização dos trabalhadores aposentados. Em decorrência disso, percebeu-se a velhice como uma categoria construída socialmente e as mazelas sofridas pelos trabalhadores aposentados brasileiros (Alvarenga, 2006; Simões, 2000).

Por sua vez, Portugal tem a participação avaliativa como um instrumento a dispor dos cidadãos para avaliar as ofertas dos serviços de saúde. No entanto, identifica-se na fala de um idoso português uma clareza de posicionamento em não querer opinar:

Olha, disso eu não gosto... um dia, aqui pediram-me para dar uma opinião sobre os enfermeiros $e$ sobre os médicos. Eu disse que estava bem, tudo bem. (Idoso, 83 anos, IP3).

Logo, o espaço para a participação avaliativa é também um espaço de conflito. De um lado, a equipe incentiva-os a participar e, de outro, os idosos o fazem por obrigação, apenas quando solicitados.

Para Fernandes e Andrade (2016) as representações sociais podem ser abstratas, impessoais ou concretas e pessoais. Assim, destacam o aspecto não apenas social, mas individual, ou seja, a representação social personificada. "Por serem elementos simbólicos, as representações sociais apontam conhecimentos, opiniões, crenças e valores incorporados nas práticas das diversas situações vivenciadas" (Fernandes \& Andrade, 2016, p. 50).

Outra questão social identificada é a relação de confiança, declarada pelo senhor que lidera uma Associação de Reformados de Portugal:

Sim, sim importante demais, mas há muita dificuldade para que isso aconteça. Veja, eu venho cá todas as manhãs, passo aqui a resolver algumas coisinhas, e não vem ninguém bater na porta... ninguém vem dizer do que precisa... quando chamo para reunião, há uns gatos pingados que aparecem, mas nem sempre vêm. Pra quê? Não querem falar, nada dizem, mas estão sempre a reclamar pelos cantos uns com os outros. Cá as pessoas não confiam umas nas outras, essa é a verdade. ...acostumaram-se assim, pois... isso não se muda de uma hora para outra, não é? (Idoso, 72 anos, IP13).

O ser humano constrói representações sociais porque precisa saber o que o faz relacionar-se com o mundo à sua volta, necessitando ajustar-se e localizar-se, identificando problemas e propondo soluções. Isto se associa ao fato de que diante de eventos, coisas, pessoas ou ideias, as suas respostas não serão apenas automatismos. O ser humano não está isolado em vazios sociais, mas sim em um mundo compartilhado com outros, nos quais se sustentará (ora convergindo, ora divergindo) para compreender, gerenciar e afrontar o mundo à sua volta (Jodelet, 2001).

Quanto à percepção sobre a participação política, a RS vinculada ao contexto social da participação se evidencia nas seguintes falas:

Se são para os idosos, eles têm que participar, pois... mas nem sempre querem eles. Os idosos não querem isso, mas também não sei se os querem. (Idosa, 69 anos, IP11). 
Em casa sou capaz de dar à língua. Em casa dou, mas fora não dou. (Idoso, 79 anos, IP10).

Sim, pois... mas há muitos que vão, há muitos idosos na política cá em Portugal, estão aí... mas eu não vou, eu é que não vou, isso é com eles lá. (Idosa, 72 anos, IP12).

Segundo Shirky (2012, p. 32), a participação não é um ritual que se reserva para os "grandes momentos", e sim "um modo de vida" que permite resolver, favoravelmente, a tensão sempre existente entre o individual e o coletivo, a pessoa e o grupo, na organização. Para o autor, uma gestão participativa pressupõe a existência de um espaço real de autonomia e o reconhecimento das diferentes competências e atribuições dos atores organizacionais. Por isso, a participação deve ser vista como um processo permanente de estabelecimento de um equilíbrio dinâmico entre todas as partes envolvidas, de forma que todos possam se sentir pertinentes no processo.

Portanto, apesar da identificação da importância da participação dos idosos nos processos de tomada de decisões por quase todos os entrevistados, identificou-se que há um hiato entre perceber essa importância e concretizá-la efetivamente. Isso se nota nas falas dos idosos, que não querem participar, ou não se criam espaços adequados para que isso aconteça.

A relação de confiança entre os portugueses tem sido apontada por Serapioni e Matos (2014) como um dos grandes problemas na consolidação da participação dos usuários em saúde. A formalização da participação dos usuários de saúde em Portugal insere-se via Associações de doentes, nomeadamente os Coletivos Sociais de Saúde (CSS). As poucas adesões nas associações enfraquecem a representatividade dos idosos em termos políticos.

Para Santos (2006), a introdução de mecanismos participativos é de extrema necessidade, visto que os espaços nos quais a cidadania pode ser exercida são influenciados, de um lado, pelo controle do Estado e, por outro, pelas organizações não estatais. Dessa forma, o cidadão pode estar vulnerável às decisões, nem sempre baseadas em sua necessidade, mas no que se identifica como o que é bom para ele. E assim, lembrando a referência de Moscovici ao falar das interações humanas, sempre que houverem interações entre duas ou mais pessoas ou entre grupos, isso irá pressupor representações. E, se este fato não for considerado ao fazermos nossas analises:

Se esse fato é menosprezado, tudo o que sobra são trocas, isto é, ações e reações, que não são específicas e, ainda mais, empobrecidas na troca. Sempre e em todos lugares, quando nós encontramos pessoas ou coisas e nos familiarizamos com elas, tais representações estão presentes. A informação que recebemos, e à qual tentamos dar um significado, está sob seu controle e não possui outro sentido para nós além do que elas dão a ele. (Moscovici, 2011, p. 40).

\section{Conclusões}

Investigar a participação dos idosos em políticas públicas em ambos os países se mostrou um exercício complexo pelos inúmeros fatores que envolvem esse processo. De início, a própria definição sobre participação se constitui como um conceito amplo e múltiplo, constatado pela forma como é interpretado pelos entrevistados. Entretanto, não foi o propósito deste trabalho estabelecer comparações entre os países, pois não se comparam diferentes realidades, apesar do inevitável modo de pensar cartesiano que influencia a sociedade. 
Nesse sentido, esta pesquisa tentou responder ao objetivo de identificar como ocorre a participação dos idosos nos espaços para implementação das políticas públicas, como esta participação é permeada por representações sociais, por significados criados no senso comum e compartilhado por grupos. E, assim, verificamos que os idosos portugueses e os brasileiros dão significados semelhantes sobre a participação social. Influenciados pelos diferentes contextos e espaços de participação, verificou-se que a participação política é mais representada nas falas dos brasileiros e a participação avaliativa pelos portugueses.

Há necessidade de mais pesquisas sobre as RS centradas na realidade social. Em nosso estudo observou-se a necessidade de ações mais amplas e integrais, direcionadas aos idosos na área da participação, para poder dar voz a estas pessoas. "A compreensão dessa realidade comum ao grupo social a ser estudado configura-se, portanto, como via de apreensão de uma realidade social singular que poderá servir de base na orientação e organização de políticas públicas eficazes". (Fernandes \& Andrade, 2016, p. 50).

Assim, acredita-se que a valorização dos idosos para participarem politicamente das ações em saúde deva ser cada vez mais incentivada por gestores responsáveis por elas. Identifica-se a necessidade que espaços verdadeiros de participação ocorram de maneira que as opiniões dos idosos sejam valorizadas em todas as instâncias e escalas das ações políticas, quer sejam nos pequenos grupos, ou nos espaços políticos formais.

\section{Referências}

Aguiar, J. C. (2016). Teoria democrática moderna. In: F. C. Vedovate \& C. B. Dellore (Org.). Sociologia: poder, política e estado (pp. 108 -142). São Paulo: Editora Moderna.

Alcântara, A. O., Camarano, A. A., \& Giacomim, K. C. (2016). Política nacional do idoso: velhas e novas questões. Rio de Janeiro: Ipea.

Alvarenga, M. C. V.-B. H. (2006). Os 147\% em questão: o movimento dos aposentados no Rio de Janeiro na década 90. Dissertação de Mestrado em Políticas Públicas. Universidade Federal Fluminense, Niterói, Rio de Janeiro, Brasil.

Bardin, L. (2007). Análise de conteúdo. Lisboa: Edições 70.

Bernardes, F. M. A. (2007). Conselho de representação: espaço para os idosos se organizarem na defesa de seus direitos. Revista Kairós, 10(2), 107-121.

Bôas, L. P. S. V. (2010). Uma abordagem da historicidade das representações sociais. Cadernos de Pesquisa, 40(140), pp. 379-405, maio/ago.

Faleiros, V. P. (2016). A política nacional do idoso em questão: passos e impasses na efetivação da cidadania. In: A. de O. Alcântara, A. A. Camarano \& K. C. Giacomin (Org.). Política Nacional do Idoso: velhas e novas questões (pp. 537-569). Rio de Janeiro: Ipea.

Fernandes, J. S. G. \& Andrade, M. S. (2016). Representações sociais de idosos sobre velhice. Arq. bras. Psicol., 68(2), pp. 48-59, ago. Disponível em: http://pepsic.bvsalud.org/scielo.php?script=sci_arttext\&pid=S180952672016000200005\&lng=pt\&nrm=iso>. Acesso em: 09 fev. 2017.

Jodelet, D. (2001). Representações sociais: um domínio em expansão. In: D. Jodelet (Org.). As representações sociais (pp. 17-44). Rio de Janeiro: EdUERJ. 
Jodelet, D. (2007). Contribuições das representações sociais para a análise das relações entre educação e trabalho. In: L. Pardal et al. (Org.). Educação e trabalho: representações, competências e trajectórias (pp. 11-26). Aveiro: Universidade de Aveiro.

Johnson, R., Escosteguy, A. C., \& Shulmann, N. (1999). O que é, afinal, Estudos Culturais? Belo Horizonte: Autêntica.

Minayo, M. C. (2010). Pesquisa social: teoria, método e criatividade (29a ed.) Petrópolis, RJ: Vozes.

Moscovici, S. (2003). Representações sociais: investigações em psicologia social. Petrópolis: Vozes.

Moscovici, S. (2007). Representações Sociais: Investigações em psicologia social. (Editado em inglês por Gerard Duveen; traduzido do inglês por Pedrinho A. Guareschi, 5aed.). Editora Vozes: Petrópolis, RJ.

Moscovici, S. (2011). Representações sociais: investigações em psicologia social. (Trad. Pedrinho A. Guareschi. 8a. Ed.) Petrópolis: Vozes.

Onu - Organização das Nações Unidas. (2014). A ONU e as pessoas idosas. Recuperado de www.onu.org.br/aonu-em-acao/a-onu-em-acao/a-onu-e-as-pessoas-idosas.

Paz, S. F. (2001). Dramas, cenas e tramas: a situação de Fóruns e Conselhos do idoso no Rio de Janeiro. Tese de Doutorado. Programa de Pós-Graduação em Educação, Universidade Estadual de Campinas, São Paulo, Brasil.

Remoaldo, P. C. A. \& Nogueira, H. (2012). Desigualdades socioterritoriais e comportamentos em saúde. Lisboa: Ed. Colibri.

Santos, B. S. (Org.). (2006). Democratizar a democracia - Os caminhos da democracia participativa. Porto: Afrontamento.

Serapioni, M. \& Matos, A. R. (2014). Saúde, participação e cidadania: experiências do Sul da Europa. Coimbra: Ed. Almedina.

Simões, J. de A. (2000). Entre o lobby e as ruas: movimento dos aposentados e politização da aposentadoria. Tese de Doutorado em Ciências Sociais. Universidade Estadual de Campinas, Campinas, Brasil.

Shirky, C. (2012). A cultura da participação. Rio de Janeiro: Ed. Zahar.

Vedovate, F. C. \& Dellore, C. B. (2016). Sociologia: poder, política e estado. São Paulo: Editora Moderna.

Veras, R. (2009). Envelhecimento populacional contemporâneo: demandas, desafios e inovações. Revista de Saúde Pública, 43(3), pp. 548-554. 